\title{
BAFF and APRIL as TNF superfamily molecules and angiogenesis parallel progression of human multiple myeloma
}

\author{
L. Bolkun • D. Lemancewicz • E. Jablonska • \\ A. Kulczynska • U. Bolkun-Skornicka • J. Kloczko • \\ J. Dzieciol
}

Received: 31 May 2013 / Accepted: 2 October 2013 / Published online: 19 October 2013

(C) The Author(s) 2013. This article is published with open access at Springerlink.com

\begin{abstract}
Tumour necrosis factor alpha (TNF- $\alpha)$ is an inflammatory cytokine with a wide spectrum of biological activity, including angiogenesis. B cell activating factor (BAFF) and a proliferation-inducing ligand (APRIL) are members of the TNF- $\alpha$ family. Vascular endothelial growth factor (VEGF), on the other hand, is one of the most characteristic proangiogenic cytokines produced by multiple cell types in multiple myeloma (MM). We have analysed BAFF and APRIL concentrations in parallel with pro-angiogenic cytokines in serum and trephine biopsy, and the bone marrow microvascular density (MVD) in 50 patients with newly diagnosed IgG MM and 24 healthy volunteers. The study showed statistically higher concentrations of BAFF, APRIL and TNF- $\alpha$, as well as VEGF and its receptor, in MM patients compared to healthy volunteers and patients in advanced stages of the disease. A statistically positive correlation between the concentration of TNF- $\alpha$ and the expression of VEGF was demonstrated, and so was a positive link between BAFF, APRIL, MVD and lactate dehydrogenase (LDH). Furthermore, we observed a significant decrease in all studied cytokines after anti-angiogenic therapy, with meaningful differences between responders (at
\end{abstract}

\footnotetext{
L. Bolkun $(\bowtie) \cdot$ D. Lemancewicz • A. Kulczynska · J. Kloczko Department of Haematology, Medical University of Bialystok, 24a Sklodowskiej-Curie, Bialystok 15-276, Poland e-mail: 1bolkun@gmail.com

D. Lemancewicz $\cdot$ J. Dzieciol

Department of Human Anatomy, Medical University of Bialystok, Bialystok, Poland

E. Jablonska

Department of Immunology, Medical University of Bialystok, Bialystok, Poland

U. Bolkun-Skornicka

Department of Pharmaceutical Technology, Medical University of Bialystok, Bialystok, Poland
}

least partial remission) and patients with stable disease. It was also established that APRIL, but not BAFF, correlated with pro-angiogenic cytokines such as VEGF with its receptor, MVD and syndecan-1. Finally, our results showed that serum BAFF and APRIL levels could be useful biomarkers of MM disease activity and its progression which suggests that APRIL could be a possible novel therapeutic target in MM.

Keywords Multiple myeloma - APRIL · BAFF · VEGF . Angiogenesis

\section{Introduction}

Multiple myeloma (MM) is a B cell malignancy originating from pre-switched, follicle centre B lymphocytes which differentiate to plasma cells accumulating in the bone marrow [1]. The crucial factors in the pathogenesis of MM include abnormalities in angiogenesis, proliferation and apoptosis [2]. An increased or abnormal level of angiogenesis has been considered for many years as a key feature of solid malignancies and associated predominantly with the pathogenesis of haematological diseases. Altered angiogenesis is one of the characteristic changes in the bone marrow (BM) myeloma microenvironment [3]. The pathophysiology of MM-induced angiogenesis is complex and involves both direct production of angiogenic cytokines by plasma cells and their induction within the microenvironment. The latter are secreted by stromal cells, endothelial cells and osteoclasts, and promote plasma cell growth, survival and migration, as well as paracrine cytokine secretion and angiogenesis in the bone marrow milieu [4]. There is increased evidence that significantly elevated levels of bone marrow angiogenesis in MM and several proangiogenic cytokines (e.g. vascular endothelial growth factor-VEGF, basic fibroblast growth factor - bFGF, hepatocyte 
growth factor- $\mathrm{HGF}$ and platelet-derived growth factorPDGF) are present in higher concentrations in myelomatous $\mathrm{BM}$ and peripheral blood and decrease after successful treatment $[5,6]$.

Tumour necrosis factor alpha (TNF- $\alpha$ ) is an inflammatory cytokine with a wide spectrum of biological activity, including angiogenesis. It influences the formation of new vessels indirectly rather than by directly promoting the sprout of endothelial cells and their growth. The release of angiogenic molecules (e.g. bFGF, PAF, VEGF-A and VEGF-C) and the upregulation of proteolytic systems (e.g. UPA) are biological events apparently triggered by TNF- $\alpha$. Moreover, TNF- $\alpha$ has been proved to increase the transcription of the VEGFR-2 gene in vascular endothelial cells. The upregulation of Sp-1 transcription by TNF- $\alpha$ appears also to lead to increased binding of this factor to the $\mathrm{Sp}-1$ binding site of the VEGFR-2 promoter region [7, 8].

$\mathrm{B}$ cell activating factor (BAFF) and a proliferationinducing ligand (APRIL), both members of the tumour necrosis factor (TNF) family, represent two of the main survival factors for immature, naive and activated B cells [9-11]. Of all the different signalling pathways activated in $\mathrm{MM}$ cells by external stimulation, the nuclear factor kappa B (NF-kB) pathway may prove to be among the most important ones. What is more, BAFF and APRIL, which can directly activate the NF- $\mathrm{kB}$ pathway, have been identified as two of the main survival factors for healthy plasma cells and MM cells [12, 13]. Depending on the B cell maturation stage, BAFF was reported to induce the antiapoptotic proteins $\mathrm{Bcl}-2, \mathrm{~A} 1$ and $\mathrm{Bcl}-\mathrm{XL}$ and to reduce the proapoptotic protein Bak [14-16]. The not yet fully understood role of BAFF, APRIL and their receptors in normal $\mathrm{B}$ cell homeostasis and in several tumour models raises the possibility of their involvement in the pathogenesis of B cell malignancies. The latest research has provided evidence that myeloma cell lines and primary myeloma cells express BAFF, APRIL and their receptors and that both of them are myeloma cell growth factors [17]. On the other hand, it was demonstrated that the main site of production for BAFF and APRIL is the BM microenvironment, and it was suggested that osteoclasts are among the predominant cell sources for BAFF and APRIL in the MM bone marrow [18, 19]. Recently, it was demonstrated that APRIL is highly produced by osteoclasts in MM patients [20]. BAFF binds to three TNF receptor family members, B cell maturation antigen (BCMA), transmembrane activator and calcium modulator and cyclophilin ligand receptor (TACI) and BAFF receptor (BAFF-R), whereas APRIL binds to BCMA, TACI and heparin-sulfate proteoglycans such as syndecan-1 [19]. Syndecan-1 is not only expressed by normal plasma cells, but it is also highly expressed by the majority of malignant plasma cells in MM patients [21]. BAFF's ability to safeguard myeloma cells against dexamethasone-induced apoptosis [10] and the possible use of BAFF as a marker of disease activity
[22] have also been recently studied. Interestingly, serum BAFF levels have been shown to serve as a useful biomarker of MM angiogenesis [22].

The objectives of the present study were to investigate circulating levels of APRIL and BAFF and to correlate them with well-known parameters of disease activity, such as TNF- $\alpha$, IL- 6 , and syndecan-1 in parallel with proangiogenic cytokines, such as VEGF with its receptor, in serum and trephine biopsy (TB). Bone marrow microvascular density (MVD) was taken under scrutiny, too.

\section{Patients}

Fifty patients with newly diagnosed IgG MM were included in the study. The median age of patients at the time of sample collection was 61 , and the range was 39-70. Twenty-eight subjects were female and 22 were male. Patients with acute or chronic infections, inflammatory processes and liver or kidney diseases had been excluded from the study. Complete blood count, erythrocyte sedimentation rate, total protein/albumin, protein and immune electrophoresis, renal function tests and skeletal surveys were performed in all cases. In addition, bone marrow aspiration and biopsy samples were examined immunohistochemically to detect plasma cells. The percentage of bone marrow infiltration by plasma cells was evaluated. At the time of diagnosis, all patients were divided into three groups based on the International Staging System, ISS (10 patients in stage I, 14 patients in stage II and 26 patients in stage III) (Table 1).

The patients' initial treatment of MM depended on their age and comorbidities. For patients below the age of 65 , the induction regimens were thalidomide-dexamethasone and cyclophosphamide (CTD) prior to a monotherapy of thalidomide $100 \mathrm{mg}$ until progression. For patients over 65 and patients with significant concurrent illness, the standard of care was chemotherapy with melphalan, prednisone and thalidomide (MPT), followed similarly by the monotherapy of thalidomide. Of the 50 patients, 24 were treated with CTD combination therapy and 26 with MPT therapy. After the treatment, patients were divided into two subgroups for further analysis: the first numbered 34 subjects (patients with response CR - complete remission [ $n=7]$, VGPR — very good partial remission $[n=10]$ and $\mathrm{PR}$-partial remission $[n=17]$ ) and the second 16 subjects (patients with SD — stable disease). Response was assessed after six cycles of chemotherapy with the same methods as for diagnosis, according to the European, International, and Autologous Bone Marrow Transplant Registries (EBMT/IBMTR/ABMTR) criteria [23].

All patient samples, along with those from normal controls, were collected with the approval of the ethics committee at the Medical University of Bialystok-approved protocol with written informed consent (agreement no. R-I-002/235/2009). 
Table 1 Clinical features of the patients

\begin{tabular}{ll}
\hline Number of patients & $N=50$ \\
Age & 61 (range 39-70) \\
Stage ISS & \\
$\quad$ I & $N=10$ \\
$\quad$ II & $N=14$ \\
$\quad$ III & $N=26$ \\
Solitary plasmocytoma & $N=0$ \\
HGB [g/dl] & $10.55 \pm 1.51$ \\
Serum protein $[\mathrm{g} / \mathrm{dl}]$ & $9.45 \pm 2.31$ \\
Serum albumin $[\mathrm{g} / \mathrm{dl}]$ & $3.36 \pm 0.70$ \\
Ca ${ }^{2+}[\mathrm{mmol} / 1]$ & $2.30 \pm 0.31$ \\
IgG [mg/dl] & $6,195.01 \pm 1,682.10$ \\
$\beta 2 \mathrm{~m}[\mathrm{~g} / \mathrm{l}]$ & $7.14 \pm 4.62$ \\
LDH [IU/l] & $246.21 \pm 159.13$ \\
$\%$ Plasma cells in TB & $40.43 \pm 24.64$ \\
$\%$ Plasma cells in smear BM & $38.53 \pm 25.51$ \\
Creatine level [mg/dl] & $0.90 \pm 0.31$ \\
PLT $\left[\times 10^{\wedge 3}\right.$ ] & $218.40 \pm 92.53$ \\
WBC $\left[\times 10^{\wedge 3}\right.$ ] & $5.84 \pm 2.43$ \\
\hline
\end{tabular}

The values are presented as mean $\pm \mathrm{SD}$

ISS International Staging System, $H G B$ haemoglobin, $\mathrm{Ca}$ calcium, $\operatorname{Ig} G$ immunoglobulin $\mathrm{G}, \beta 2 m$ beta-2-microglobulin, $L D H$ lactate dehydrogenase, $T B$ trephine biopsy, $B M$ bone marrow, $P L T$ platelet count, $W B C$ white blood cells

The control group consisted of 24 age- and sex-matched healthy volunteers.

\section{Methods}

Soluble concentration of cytokines

Quantitative assessments of cytokines were performed by means of ELISA assays. Soluble APRIL concentrations were measured with Human APRIL (Platinum ELISA, eBioscience, Austria). Soluble BAFF, IL-6 and TNF- $\alpha$ were evaluated using commercially available test kits (Quantikine ${ }^{\circledR}$, R\&D kits, Minneapolis, MN, USA). Soluble VEGF and sVEGR2 were measured using commercially available test kits (Quantikine ${ }^{\circledR}$ ELISA, R\&D Systems, Minneapolis, MN, USA) as well.

Immunohistochemistry for syndecan-1 and for VEGF and its receptor

Immunohistochemical examinations were conducted with specific antibodies. Primary antibodies were used by dilution according to the manufacturer's instructions: a dilution of 1:10 for VEGF (DakoCytomation), a dilution of 1:50 for VEGFR2
(Santa Cruz Biotechnology, Santa Cruz, CA), a dilution of 1:50 for TNF- $\alpha$ (Santa Cruz Biotechnology, Santa Cruz, CA) and a dilution of 1:100 for syndecan-1, CD138 (catalogue no. M7228, monoclonal mouse, clone Mi15, DakoCytomation). All sections required microwave heating for receptor retrieval. The detecting kit was LSAB + Kits (DakoCytomation). DAB (3,3'-diaminobenzidine) was used as a chromogen. If the reaction was positive, brown-coloured antigen-antibody complexes appeared in the position of protein receptors. The intensity of the positive reaction was defined according to the scale described by Kumar et al. [24]: '-' indicates no staining, '+' weak staining (0-30\% plasma cells positive), ' ++ ' weak to moderate staining (31-60\% plasma cells positive), and ' +++ ' strong staining (more than $60 \%$ plasma cells positive).

Measurement and grading of bone marrow angiogenesis

MVD was assessed in the TB samples by means of the previously described methods used by other investigators $[25,26]$. All estimations were performed in a blinded manner. For simple grading, slides were scanned at $\times 100, \times 200$ and $\times 400$ magnification, and based on the extent of microvessel staining, each slide was assigned an angiogenesis grade as described previously: low, intermediate or high [25]. Briefly, bone marrow TB specimens stained for CD34 were classified as low-, intermediate- and high-grade angiogenesis, based on the visual evaluation of the entire stained field under $\times 200$ magnification. The assessment of low-, intermediate- and high-grade angiogenesis was reliant primarily on the visual impression of the number of CD34-positive microvessels observed in the entire biopsy section. The average number of vessels stained with $\mathrm{CD} 34$ was first scanned at $\times 100$ magnification to determine three hot spots defined as areas with the maximum number of microvessels. The hot spots were then examined at high-powered fields $(\times 400$ magnification) using a $\times 10$ ocular and $\times 40$ objective lens. Large vessels and vessels in the periosteum or bone were excluded. Areas of staining with no discrete breaks counted as a single vessel. The presence of a lumen was not required.

\section{Statistical analysis}

Results were expressed as means \pm standard deviation (SD). The non-parametric Kruskal-Wallis test and one-way analysis of variance (ANOVA) were applied to test for different stages. Student's $t$ test was used for a pairwise comparison of subgroups. Comparisons between the MM and the control groups were performed using the non-parametric Mann-Whitney test. Spearman's order correlation coefficient was applied to determine links between the measured parameters. $p$ values below 0.05 were considered to be statistically significant. 


\section{Results}

Mean $( \pm$ SD) serum values of BAFF, APRIL, IL-6, TNF- $\alpha$, VEGF and sVGFR2 are listed in Table 2. Pre-treatment myeloma patients had a significantly higher serum concentration of BAFF, APRIL, VEGF, sVEGFR2, IL-6 and TNF- $\alpha$ compared to healthy volunteers: for BAFF, TNF- $\alpha$ and IL-6 $(p<$ $0.0001)$; for APRIL $(p=0.03)$ and for VEGF and sVEGFR2 $(p<0.01)$, respectively (Table 2$)$.

For the purposes of this study, patients in stage I MM and patients in stages II and III (according to the ISS) were analysed separately. MM patients in advanced disease stage III had higher serum levels of all the studied parameters in comparison to those in stage I: for APRIL, $p=0.03$; BAFF, $p=0.0008$; TNF- $\alpha, p=0.002$; IL-6, $p=0.001$ and VEGF and sVEGFR2, $p=0.001$, respectively. Furthermore, the study revealed statistically significant differences in the expression of syndecan-1, VEGF and TNF- $\alpha, p=0.003, p=0.007$ and $p=0.02$, respectively, in TB between stages III and I. Meaningful dissimilarities were also found with respect to MVD, $p=0.04$. Additionally, our analyses exhibited marked differences in the concentration of BAFF, $p=0.01$; TNF- $\alpha$, $p=0.04$ and MVD, $p=0.01$ between stages I and II and differences of the concentration of BAFF, $p=0.002$; VEGF, $p=0.01$ and sVEGFR2, $p=0.03$ between stages II and III. Equally worth noticing were some other statistically significant correspondences. First of all, the concentration of all the studied cytokines in the group of newly diagnosed MM patients differed sharply from that of patients after anti- angiogenic regiment chemotherapy. Secondly, pronounced differences were observed between the subgroup of patients with PR + VGPR + CR (the first subgroup) and patients with $\mathrm{SD}$ (the second subgroup). The concentrations of BAFF, VEGF, its receptor and IL-6 $(p=0.01)$ and APRIL $(p=0.04)$ and that of TNF- $\alpha, p=0.02$ and expression of syndecan- 1 and $\operatorname{MVD}(p=0.01$ and $p=0.02$ ) were found to be lower in the former compared to the latter. No differences, however, were detected in the expression of VEGF and TNF- $\alpha$ in TB, $p>$ 0.05 (Table 3).

We subsequently correlated each cytokine under scrutiny with a selection of well-known parameters of prognosis and tumour load in MM listed in Table 1. The study demonstrated statistically positive correspondences between the concentration of total protein and VEGF (rho $=0.4, p=0.01$ ), MVD (rho $=0.58, p=0.003)$, as well as TNF- $\alpha(\mathrm{rho}=0.31, p=$ $0.04)$ and VEGF expression ( $\mathrm{rho}=0.31, p=0.04)$. In addition, it revealed a significantly negative correlation between the concentration of VEGFR2 and $\beta 2 \mathrm{~m}(\mathrm{rho}=-0.34, p=0.045)$ and a positive one between BAFF, APRIL, MVD and LDH, $p=0.001$ and $p=0.0003, p=0.02$, respectively.

Apart from the abovementioned observations, our analysis exhibited some statistically meaningful divergences between the studied ligands. The concentration of APRIL was found to correlate significantly and positively with the concentration of VEGF (rho=0.54, $p=0.002$, Fig. 1 ) and IL-6 (rho=0.41, $p=$ $0.005)$, and the expression of VEGF $(\mathrm{rho}=0.4, p=0.008)$, syndecan-1 (rho=0.49, $p=0.04$, Fig. 2) and MVD (rho= $0.64, p=0.0001$, Fig. 3$)$, but not with TNF- $\alpha($ rho $=0.26, p=$

Table 2 The mean values of chosen parameters of new diagnosed MM patients

\begin{tabular}{|c|c|c|c|c|c|}
\hline \multirow[t]{3}{*}{ Cytokine } & \multicolumn{5}{|l|}{ No. of patients } \\
\hline & \multirow{2}{*}{$\begin{array}{l}\text { Newly diagnosed patients, } \\
N=50\end{array}$} & \multirow{2}{*}{$\begin{array}{l}\text { Healthy volunteers, } \\
N=24\end{array}$} & \multicolumn{3}{|l|}{ Newly diagnosed patients } \\
\hline & & & Patients at I ISS, $N=10$ & Patients at II ISS, $N=14$ & Patients at III ISS, $N=26$ \\
\hline BAFF $[\mathrm{pg} / \mathrm{ml}]$ & $904.63 \pm 439.8$ & $309.2 \pm 116.1^{*}$ & $589.09 \pm 410.6$ & $880.69 \pm 317.9^{* *}$ & $1,276.12 \pm 505.4^{* * *}$ \\
\hline APRIL [ng/ml] & $2.69 \pm 0.4$ & $1.59 \pm 0.41^{*}$ & $2.12 \pm 0.37$ & $2.55 \pm 0.42$ & $3.09 \pm 0.31 * * *$ \\
\hline $\mathrm{TNF}[\mathrm{pg} / \mathrm{ml}]$ & $20.58 \pm 8.2$ & $13.73 \pm 4.08^{*}$ & $16.8 \pm 3.61$ & $21.57 \pm 6,72^{* *}$ & $20.9 \pm 12.28 * * *$ \\
\hline IL-6 [pg/ml] & $10.99 \pm 9.0$ & $1.96 \pm 0.46^{*}$ & $8.58 \pm 4.63$ & $9.85 \pm 4.73$ & $12.63 \pm 10.76^{* * *}$ \\
\hline VEGF [pg/ml] & $240.91 \pm 121.0$ & $111.2 \pm 70.4^{*}$ & $189.7 \pm 112.4$ & $213.78 \pm 56.52$ & $299.78 \pm 127.05 * * *$ \\
\hline sVEGFR2 [pg/ml] & $6,990.2 \pm 2,704.5$ & $2,143.4 \pm 847.1^{*}$ & $4,883.4 \pm 1,336.5$ & $6,460.8 \pm 1,750.7$ & $9,225.3 \pm 1,120.9^{* * *}$ \\
\hline VEGF expression & $26.09 \pm 14.8$ & ND & 21.75.11.48 & $25.15 \pm 14.09$ & $32.15 \pm 16.05^{* * *}$ \\
\hline TNF expression & $11.62 \pm 7.5$ & ND & $9.05 \pm 4.18$ & $12.33 \pm 10.58$ & $21.57 \pm 5.77 * * *$ \\
\hline MVD & $19.74 \pm 6.6$ & ND & $15.77 \pm 4.27$ & $20.88 \pm 5.31^{* *}$ & $22.9 \pm 8.66 * * *$ \\
\hline $\begin{array}{l}\text { Sydecan-1 (CD138) } \\
\text { expression }\end{array}$ & $73.12 \pm 22.9$ & ND & $58.75 \pm 20.1$ & $72.5 \pm 17.07$ & $75.66 \pm 25.9 * * *$ \\
\hline
\end{tabular}

The values are presented as mean $\pm \mathrm{SD}$

$M M$ multiple myeloma, ISS International Staging System, $B A F F$ B cell activating factors, $A P R I L$ a proliferation-inducing ligand, $T N F$ tumour necrosis factor, $I L-6$ interleukin 6,VEGF vascular endothelial growth factor, $s V E G F R 2$ soluble vascular endothelial growth factor receptor, $M V D$ microvascular density, $N D$ not done

${ }^{*} p<0.05$ between MM patients and healthy volunteers; ${ }^{* *} p<0.05$ between stage I and II MM patients; $* * *<0.05$ between stage I and III MM patients 
Table 3 The mean values of chosen parameters of MM patients before and after treatment

\begin{tabular}{|c|c|c|c|c|}
\hline \multirow[t]{3}{*}{ Cytokine } & \multicolumn{4}{|l|}{ No. of patients } \\
\hline & \multirow[t]{2}{*}{ New diagnosed patients, $N=50$} & \multicolumn{3}{|l|}{ Patients after treatment } \\
\hline & & After the treatment, $N=50$ & With PR + VGPR + CR, $N=34$ & With SD, $N=16$ \\
\hline $\mathrm{BAFF}[\mathrm{pg} / \mathrm{ml}]$ & $904.63 \pm 439.8$ & $721.04 \pm 82.1^{*}$ & $511.21 \pm 221.3$ & $982.2 \pm 422.02 * *$ \\
\hline APRIL [ng/ml] & $2.69 \pm 0.4$ & $1.54 \pm 1.01^{*}$ & $1.12 \pm 0.32$ & $2.59 \pm 1.33 * *$ \\
\hline $\mathrm{TNF}[\mathrm{pg} / \mathrm{ml}]$ & $20.58 \pm 8.2$ & $15.11 \pm 4.29^{*}$ & $10.37 \pm 3.1$ & $18.56 \pm 11.36^{* *}$ \\
\hline IL-6 [pg/ml] & $10.99 \pm 9.0$ & $6.12 \pm 3.78 .1 *$ & $4.93 \pm 1.07$ & $12.6 \pm 3.19 * *$ \\
\hline VEGF [pg/ml] & $240.91 \pm 121.0$ & $176.03 \pm 56.09^{*}$ & $134.07 \pm 54.16$ & $245.44 \pm 43.45^{* *}$ \\
\hline sVEGFR2 [pg/ml] & $6,990.2 \pm 2,704.5$ & $4,359.4 \pm 1,865.4^{*}$ & $3,942.3 \pm 1,920.1$ & $5,129.8 \pm 3,221.9 * *$ \\
\hline VEGF expression & $26.09 \pm 14.8$ & $23.12 \pm 11.3$ & $22.5 \pm 10.4$ & $24.01 \pm 12.4$ \\
\hline TNF expression & $11.62 \pm 7.5$ & $9.31 \pm 5.32$ & $8.76 \pm 4.89$ & $9.56 \pm 5.49$ \\
\hline MVD & $19.74 \pm 6.6$ & $11.65 \pm 4.30$ & $9.65 \pm 3.11$ & $13.5 \pm 4.72 * *$ \\
\hline Syndecan-1 (CD138) expression & $73.12 \pm 22.9$ & $28.12 \pm 16.88^{*}$ & $16.22 \pm 11.3$ & $32.32 \pm 56.1 * *$ \\
\hline
\end{tabular}

The values are presented as mean $\pm \mathrm{SD}$

$M M$ multiple myeloma, ISS International Staging System, $B A F F$ B cell activating factors, $A P R I L$ a proliferation-inducing ligand, $T N F$ tumour necrosis factor, $I L-6$ interleukin 6,VEGF vascular endothelial growth factor, $s V E G F R 2$ soluble vascular endothelial growth factor receptor, $M V D$ microvascular density

${ }^{*} p<0.05$ between before and after treatments of MM patients; $* * p<0.05$ between patients with response and stable disease

0.31). The study also showed a positive correlation between the concentration of BAFF and TNF- $\alpha(\mathrm{rho}=0.39, p=0.01)$ and IL-6 (rho $=0.42, p=0.008)$. We did find, however, a meaningful link between the concentration of BAFF and the expression of VEGF (rho $=0.12, p=0.3)$, syndecan-1 (rho= $0.27, p=0.22)$ and MVD (rho $=0.31, p=0.2)$. In addition, our research revealed a positive correlation between MVD, sVEGFR2 $(\mathrm{rho}=0.55, p=0.01)$ and TNF- $\alpha(\mathrm{rho}=0.42$, $p=0.04)$.

\section{Discussion}

Angiogenesis, the biological phenomenon of new blood vessel formation, increases significantly in the bone marrow along with a spectrum of plasma cell disorders, and becomes a prominent feature in active MM [3]. VEGF is one of the most characterized pro-angiogenic cytokines produced by multiple cell types in MM [27]. VEGF acts on vascular endothelial cells and stimulates stromal cells to produce
Fig. 1 Correlation between serum concentration of VEGF and serum concentration of APRIL in patients newly diagnosed with multiple myeloma

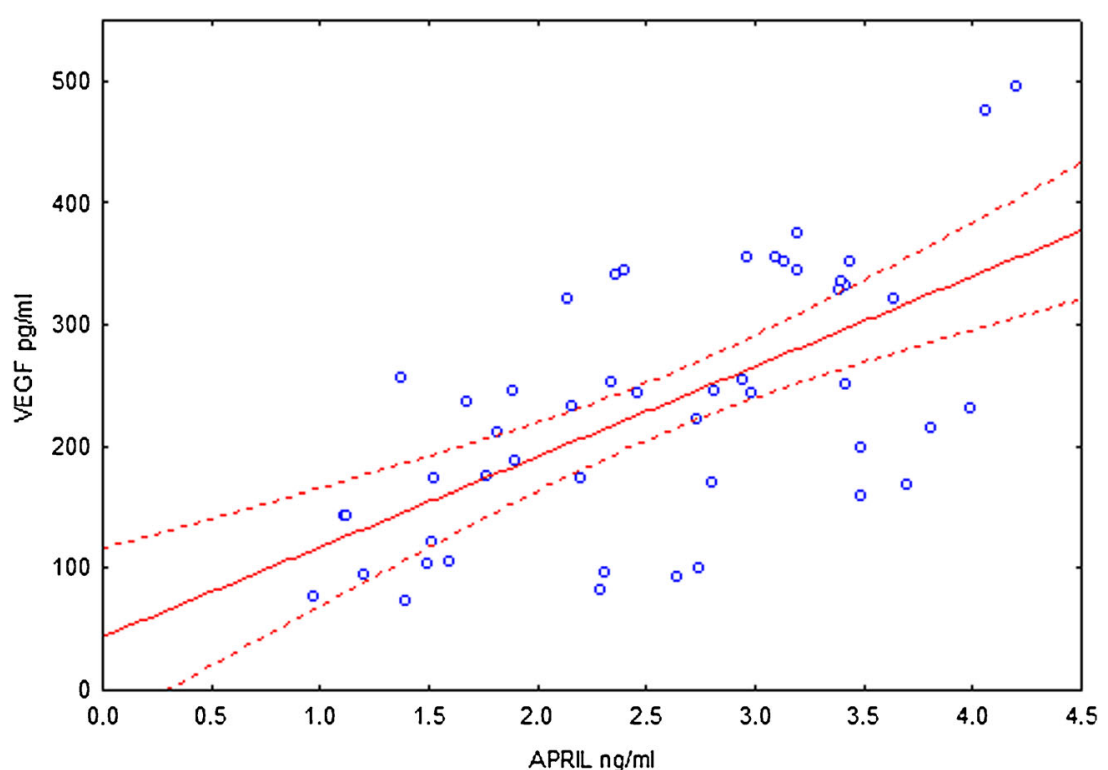


Fig. 2 Correlation between expression of syndecan-1 (CD138) and serum concentration of APRIL

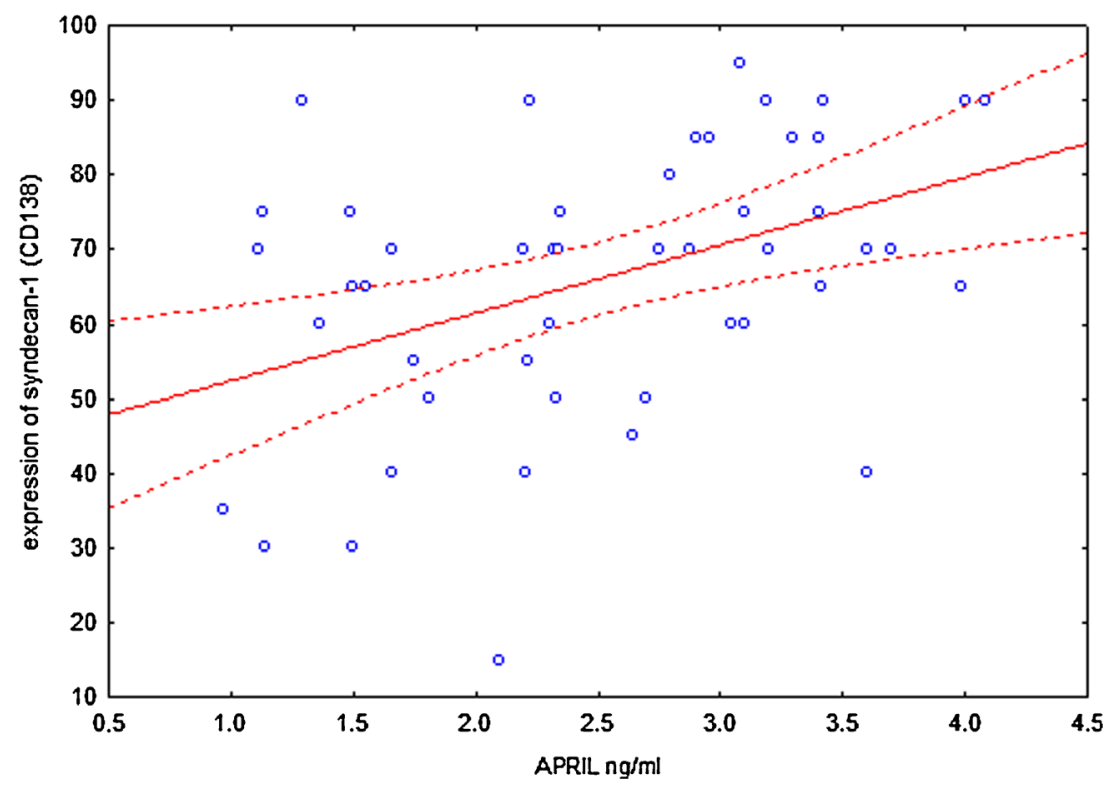

interleukin-6, which in turn stimulates increased secretion of VEGF and its receptors. Thus, VEGF acts as a regulator of cellular growth, survival and migration [27]. Yet, still very little is known about the molecular signalling pathways involved in TNF-induced angiogenesis. Speculating over the possible mechanisms, some researchers have suggested that TNF- $\alpha$ directly activates endothelial cell (EC) migratory pathways [28] through transactivation between the endothelial/ epithelial tyrosine kinase Etk and VEGF receptor 2 (VEGFR2) [29]. TNF- $\alpha$ has also been reported to mediate macrophage-induced angiogenesis [30]. The angiogenic activity triggered by activated murine peritoneal macrophages is completely neutralized by a polyclonal antibody to TNF- $\alpha$, implying that immunological features are common to both TNF- $\alpha$ and the protein responsible for macrophage-derived angiogenic activity [30]. TNF- $\alpha$ stimulated angiogenesis in cultured ECs and in cornea angiogenesis assays [28], and the chronic expression of TNF- $\alpha$ at low levels in a human TNF transgenic mice model has also been shown to induce joint angiogenesis and inflammatory arthritis [31]. In addition, $\mathrm{TNF}-\alpha$ is known to promote angiogenesis through its ability to synergize VEGF-induced vessel permeability, a requisite initial event for plasma exudation and fibrin clot formation, a matrix permissive for angiogenesis [32]. TNF- $\alpha$ is also capable of
Fig. 3 Correlation between bone marrow microvascular density and serum concentration of APRIL in patients newly diagnosed with multiple myeloma

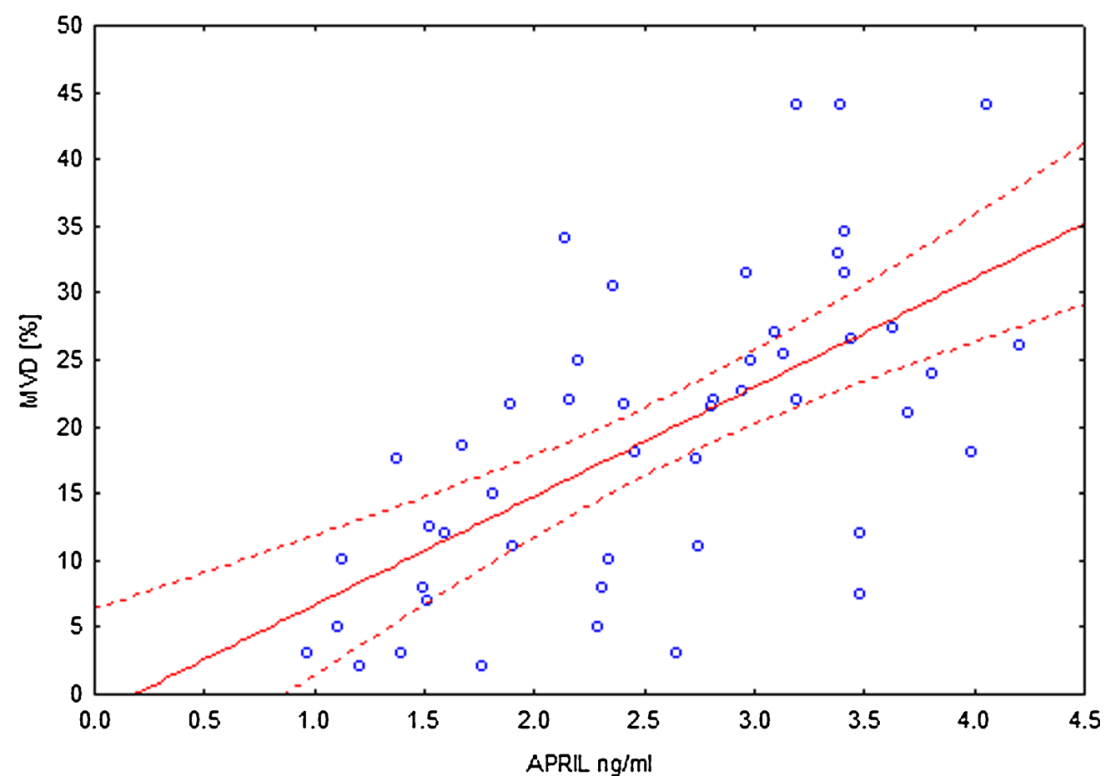


inducing gene expression of pro-angiogenic molecules, such as VEGF and its receptors (VEGFRs) [7]. Indeed, the cellular VEGF mRNA level is potently enhanced in response to TNF- $\alpha$, probably due to transcriptional activation mediated by the transcription factor SP-1 [32], leading to the induction of a paracrine loop for neovascularisation under pathological conditions, including cancer.

In the present study, we found MM patients to have higher serum levels of VEGF and its receptor compared to controls, which falls in line with previous reports [33]. Even more importantly, we confirmed the increased concentration of VEGF and its receptor, as well as the expression of VEGF in TB in advancing disease stages since patients in stage III had significantly higher levels of all cytokines compared to those in stage I. The former showed decreased values only after therapy, with meaningful differences between the responders and patients with stable disease. In accordance with the published data, VEGF has again transpired to be one of the angiogenesis activators that significantly respond to successful treatment [33]. There are, however, contradictory reports on the correlation between the level of VEGF and prognosis. Mileskhin et al. reported that high levels of VEGF were associated with response rate in patients treated with thalidomide [34]. On the other hand, Cibeira and collaborators have not confirmed any correlation between the response rate and VEGF level [35]. One way or another, determining VEGF activity on the basis of serum levels is not a reliable marker of angiogenesis as serum VEGF is not only released by myeloma cells but also by leukocytes and platelets during blood clotting [36]. The measurement of MVD utilizing immunohistochemistry has provided an objective method for assessing the degree of neovascularisation and has been shown to be a significant and independent prognostic indicator of disease activity in various malignancies including MM [4, 5]. In our study, we observed that pre-treatment MVD of stage III patients was significantly higher than that of stage I and II patients, and this finding emphasizes the relevance of MVD to myeloma progression. We also found a meaningful decrease in MVD in TB for patients who responded to treatment. Some authors failed to demonstrate any correlation between MVD at diagnosis and response to initial therapy (standard chemotherapy, high-dose therapy or thalidomide) and thus concluded that mechanisms other than drug resistance are responsible for the prognostic value of marrow angiogenesis [26]. In our research, we established significant differences in MVD between patients with at least partial response compared to MM patients who did not respond to the anti-angiogenic therapy. In line with the findings of one previous study [37], our results suggest angiogenesis and primary resistance to therapy to be related features of biologically more aggressive disease. Moreover, patients who achieved remission after chemotherapy showed a highly significant decrease in MVD in comparison to their pretreatment levels [37]. A decrease in MVD after chemotherapy could be partly mediated by a reduction in the release of angiogenic factors from myeloma cells and by the direct toxic effect of the chemotherapy on ECs [38]. Still, despite the decrease in MVD, its level still remained higher than normal even after effective treatment [38].

Furthermore, our analyses showed a significant correlation between MVD and LDH, which, at high levels, is a biochemical marker of increased tumour mass. An increased LDH value in newly diagnosed MM patients is a predictor of poor prognosis that should be considered for early intensive treatment $[37,38]$. We also exhibited a strong link between MVD and serum levels of TNF- $\alpha$. It is worth noticing here that previous work proved TNF- $\alpha$ to be a potent inducer of IL-6 production by myeloma cells and one that may play an important role in the pathogenesis of human MM [39].

To the best of our knowledge, there is no data describing the correlation between pro-angiogenic cytokines and BAFF and APRIL, both members of the TNF- $\alpha$ family which play an important role not only in B cell development and immunity but also in normal plasma cells [40]. Importantly, BAFF can clearly stimulate the survival of plasma cells under in vitro conditions, yet it seems superfluous in the bone marrow in vivo. Selective local production of APRIL in the bone marrow appears to skew the in vivo dependence of this survival response towards APRIL. This latter idea is further supported by a recent observation that megakaryocytes, which produce significant amounts of APRIL [41], are a crucial constituent of the bone marrow niche for plasma cells [42]. Therefore, such selective local production of APRIL may be essential for the survival of lymphoid malignancies in the bone marrow. In addition, being expressed in MM cells, BAFF can be detected in the serum of MM patients, suggesting an autocrine loop of stimulation from these tumour cells [41]. BAFF has been reported to be secreted mainly by the bone marrow stromal cells, and plasma cell adhesion to them augments its secretion, resulting in NF- $\mathrm{KB}$ activation and MAPK and AKT phosphorylation [10].

In the undertaken study, we found MM patients to have higher serum levels of BAFF and APRIL compared to controls, which falls in line with the previous reports [22, 43]. Furthermore, we confirmed the increased concentration of BAFF and APRIL in advancing disease stages since patients in stage III had significantly higher levels of both ligands compared to those in stage I and II. Additionally, we observed meaningful changes after anti-angiogenic treatment. Statistical differences between patients with at least partial remission and no responders must also be noted.

Furthermore, we found a correlation between both ligands and LDH, which is an important prognostic variable in many haematological malignancies [44] and, most importantly, the growth factor IL-6, which is a pleiotropic cytokine with multiple biological activities in vitro and in vivo, including human myeloma cell proliferation, differentiation and protection 
against drug-induced cytotoxicity [44]. Since serum levels of IL- 6 and LDH reflect the activity of MM, it is possible that the elevated serum BAFF and APRIL concentrations found in advanced MM stages may be related to the growth of myeloma cells. This does not come as a surprise since BAFF and APRIL are well-known stimulator factors for B cell homeostasis and survival, through the activation of NF- $\mathrm{KB}$ pathways. Atacicept, a specific inhibitor of BAFF and APRIL that is a fusion protein composed of the human IgG Fc portion and the extracellular, ligand-binding portion of the TACI receptor in phase I study of relapsed/refractory MM or active Waldenström's macroglobulinemia has been tried recently. The decrease in polyclonal Ig with and bone marrow density, myeloma cell numbers and plasma concentrations of soluble CD138 with atacicept suggested that BAFF and APRIL may by critical factors for the long-term survival of plasma cells. It was also suggested that atacicept inhibits MM cell survival within the bone marrow microenvironment [45].

It has been recently shown that the PCNA proliferative index increases in parallel with tumour burden and correlates with BAFF concentration in MM patients, which suggests that BAFF may be used as a marker of disease progression [46]. Furthermore, researchers have found a positive link between MVD and BAFF concentration [46]. In our study, we did not detect the association between the concentration of MVD and BAFF. We did, however, determine a link of the second TNF- $\alpha$ molecule, APRIL and MVD. In addition, our study revealed a positive correlation between the concentration of APRIL and VEGF and its receptor in MM patients. It also established a link between APRIL concentration and VEGF expression in TB. The analyses did not exhibit, however, a significant association between VEGF with its receptor and BAFF. The differences in our data may be due to the different mechanisms of action between BAFF and APRIL that were previously presented. In addition, MM cells variably express the three specific receptors-BCMA, BAFF-R and TACIand express syndecan- 1 as a co-receptor for APRIL and TACI, but not for BCMA, BAFF or BAFF-R [19]. Syndecan-1 can confer a specific bridge to mediate an APRIL-TACI loop in the biology of primary MM cells. It was demonstrated that MM cells can bind high amounts of APRIL and soluble TACI through cell surface syndecan-1 and that this binding to syndecan-1 is critical for APRIL myeloma growth and survival [47]. Our study revealed statistically significant differences in the expression of syndecan- 1 and serum levels of APRIL between stages III and I according to ISS. Furthermore, we found a positive correlation between the expression of syndecan- 1 and APRIL and that it could enhance the growth and survival of MM cells.

In conclusion, our results confirmed that serum BAFF and APRIL levels could be a useful biomarker of MM disease activity and progression. In addition, we showed a positive correlation between the concentrations of pro-angiogenic cytokines: VEGF with its receptor and the concentration of APRIL, but not BAFF. Both ligands may therefore be a novel therapeutic target in MM.

Conflict of interest The authors declare that they have no conflict of interest.

Open Access This article is distributed under the terms of the Creative Commons Attribution License which permits any use, distribution, and reproduction in any medium, provided the original author(s) and the source are credited.

\section{References}

1. Pratt G (2002) Molecular aspects of multiple myeloma. Mol Pathol 55:273-283

2. Hallek M, Bergsagel P, Anderson KC (1998) Multiple myeloma: increasing evidence for a multistep transformation process. Blood 91(1):3-21

3. Rajkumar VS, Mesa R, Fonseca R, Shroeder G, Plevak M, Dispenzieri A, Lacy MQ, Lust JA, Witzig TE, Gertz MA, Kyle RA, Russell SJ, Greipp PR (2002) Bone marrow angiogenesis in 400 patients with monoclonal gammopathy of undetermined significance, multiple myeloma, and primary amyloidosis. Clin Cancer Res 8(7):2210-2216

4. Vacca A, Ria R, Ribatti D, Semeraro F, Djonov V, Raimondo F, Dammacco F (2003) A paracrine loop in the vascular ebnothelial growth factor pathway triggers tumor angiogenesis and growth in multiple myeloma. Haematologica 88(2):176-185

5. Hatjiharissi E, Terpos E, Papaioannou M, Hatjileontis C, Kaloutsi V, Galaktidou G, Gerotziafas G, Christakis J, Zervas K (2004) The combination of intermediate doses of thalidomide and dexamethasone reduces bone marrow micro-vessel density but not serum levels of angiogenic cytokines in patients with refractory/relapsed multiple myeloma. Hematol Oncol 22:159-168

6. Alexandrakis MG, Passam FH, Boula A, Christophoridou A, Aloizos G, Roussou P, Kyriakou DS (2003) Relationship between circulating serum soluble interleukin-6 receptor and the angiogenic cytokines basic fibroblast growth factor and vascular endothelial growth factor in multiple myeloma. Ann Hematol 82:19-23

7. Giraudo E, Primo L, Audero E, Gerber HP, Koolwijk P, Soker S, Klagsbrun M, Ferrara N, Bussolino F (1998) Tumor necrosis factoralpha regulates expression of vascular endothelial growth factor receptor- 2 and of its co-receptor neuropilin- in human vascular endothelial cells. J Biol Chem 273:22128-22135

8. Ristimaki A, Narko K, Enholm B, Joukov V, Alitalo K (1998) Proinflammatory cytokines regulate expression of the lymphatic endothelial mitogen vascular endothelial growth factor-C. J Biol Chem 273:8413-8418

9. Schneider P, MacKay F, Steiner V, Hofmann K, Bodmer JL, Holler N, Ambrose C, Lawton P, Bixler S, Acha-Orbea H, Valmori D, Romero P, Werner-Favre C, Zubler RH, Browning JL, Tschopp J (1999) BAFF, a novel ligand of the tumor necrosis factor family, stimulates B cell growth. J Exp Med 189(11):1747-1756

10. Moreaux J, Legouffe E, Jourdan E, Quittet P, Reme T, Lugagne C, Moine P, Rossi JF, Klein B, Tarte K (2004) BAFF and APRIL protect myeloma cells from apoptosis induced by interleukin 6 deprivation and dexamethasone. Blood 103:3148-3157

11. Tai YT, Li XF, Breitkreutz I, Song W, Neri P, Catley L, Podar K, Hideshima T, Chauhan D, Raje N, Schlossman R, Richardson P, Munshi NC, Anderson KC (2006) Role of B-cell-activating factor 
in adhesion and growth of human multiple myeloma cells in the bone marrow microenvironment. Cancer Res 66(13):6675-6682

12. Caers J, Van Valckenborgh E, Menu E, Van Camp B, Vanderkerken $\mathrm{K}$ (2008) Unraveling the biology of multiple myeloma disease: cancer stem cells, acquired intracellular changes and interactions with the surrounding micro-environment. Bull Cancer 95:301-313

13. Mitsiades CS, Mitsiades N, Poulaki V, Schlossman R, Akiyama M, Chauhan D, Hideshima T, Treon SP, Munshi NC, Richardson PG, Anderson KC (2002) Activation of NF-kappaB and upregulation of intracellular anti-apoptotic proteins via the IGF-1/Akt signaling in human multiple myeloma cells: therapeutic implications. Oncogene 21(37):5673-5683

14. Do RK, Hatada E, Lee H, Tourigny MR, Hilbert D, Chen-Kiang S (2000) Attenuation of apoptosis underlies B lymphocyte stimulator enhancement of humoral immune response. J Exp Med 192:953-964

15. Hsu BL, Harless SM, Lindsley RC, Hilbert DM, Cancro MP (2002) Cutting edge: BLyS enables survival of transitional and mature B cells through distinct mediators. J Immunol 168: 5993-5996

16. Batten M, Groom J, Cachero TG, Qian F, Schneider P, Tschopp J, Browning JL, Mackay F (2000) BAFF mediates survival of peripheral immature B lymphocytes. J Exp Med 192:1453-1466

17. Novak AJ, Darce JR, Arendt BK, Harder B, Henderson K, Kindsvogel W, Gross JA, Greipp PR, Jelinek DF (2004) Expression of BCMA, TACI, and BAFF-R in multiple myeloma: a mechanism for growth and survival. Blood 103:689-694

18. Moreaux J, Cremer FW, Reme T, Raab M, Mahtouk K, Kaukel P, Pantesco V, De Vos J, Jourdan E, Jauch A, Legouffe E, Moos M, Fiol G, Goldschmidt H, Rossi JF, Hose D, Klein B (2005) The level of TACI gene expression in myeloma cells is associated with a signature of microenvironment dependence versus a plasmablastic signature. Blood 106(3):1021-1030

19. Abe M, Kido S, Hiasa M, Nakano A, Oda A, Amou H, Matsumoto T (2006) BAFF and APRIL as osteoclast-derived survival factors for myeloma cells: a rationale for TACI-Fc treatment in patients with multiple myeloma. Leukemia 20(7):1313-1315

20. Moreaux J, Hose D, Kassambara A, Reme T, Moine P, Requirand G, Goldschmidt H, Klein B (2011) Osteoclast-gene expression profiling reveals osteoclast-derived CCR2 chemokines promoting myeloma cell migration. Blood 117(4):1280-1290

21. Costes V, Magen V, Legouffe E, Durand L, Baldet P, Rossi JF, Klein B, Brochier J (1999) The Mi15 monoclonal antibody (anti-syndecan1 ) is a reliable marker for quantifying plasma cells in paraffinembedded bone marrow biopsy specimens. Hum Pathol 30(12): 1405-1411

22. Fragioudaki M, Boula A, Tsirakis G, Psarakis F, Spanoudakis M, Papadakis IS, Pappa CA, Alexandrakis MG (2012) B cell-activating factor: its clinical significance in multiple myeloma patients. Ann Hematol 91(9):1413-1418

23. Gertz M, Giralt S, Jagannath S, Vesole D (1998) Criteria for evaluating disease response and progression in patients with multiple myeloma treated with high-dose therapy and haematopoietic stem cell transplantation. Br J Haematol 102:1115-1123

24. Kumar S, Witzig TE, Timm M, Haug J, Wellik L, Fonseca R, Greipp PR, Rajkumar SV (2003) Expression of VEGF and its receptors by myeloma cells. Leukemia 17(10):2025-2031

25. Rajkumar SV, Leong T, Roche PC, Fonseca R, Dispenzieri A, Lacy MQ, Lust JA, Witzig TE, Kyle RA, Gertz MA, Greipp PR (2000) Prognostic value of bone marrow angiogenesis in multiple myeloma. Clin Cancer Res 6(8):3111-3116

26. Rajkumar SV, Witzig TE (2000) A review of angiogenesis and antiangiogenic therapy with thalidomide in multiple myeloma. Cancer Treat Rev 26(5):351-362

27. Podar K, Anderson K (2005) The pathophysiologic role of VEGF in hematologic malignancies: therapeutic implication. Blood 105(4): $1383-1395$
28. Sarma V, Wolf FW, Marks RM, Shows TB, Dixit VM (1992) Cloning of a novel tumor necrosis factor-alpha-inducible primary response gene that is differentially expressed in development and capillary tube-like formation in vitro. J Immunol 148:3302-3312

29. Zhang R, Xu Y, Ekman N, Wu Z, Wu J, Alitalo K, Min W (2003) Etk/ Bmx transactivates vascular endothelial growth factor 2 and recruits phosphatidylinositol 3-kinase to mediate the tumor necrosis factorinduced angiogenic pathway. J Biol Chem 278:51267-51276

30. Aggarwal BB, Shishodia S, Sandur SK, Pandey MK, Sethi G (2006) Inflammation and cancer: how hot is the link? Biochem Pharmacol 72:1605-1621

31. Keffer J, Probert L, Cazlaris H, Georgopoulos S, Kaslaris E, Kioussis D, Kollias G (1991) Transgenic mice expressing human tumour necrosis factor: a predictive genetic model of arthritis. EMBO J 10: 4025-4031

32. Lee MJ, Thangada S, Claffey KP, Ancellin N, Liu CH, Kluk M, Volpi M, Sha'afi RI, Hla T (1999) Vascular endothelial cell adherents junction assembly and morphogenesis induced by sphingosine-1phosphate. Cell 99:301-312

33. Pour L, Svachova H, Adam Z, Almasi M, Buresova L, Buchler T, Kovarova L, Nemec P, Penka M, Vorlicek J, Hajek R (2010) Levels of angiogenic factors in patients with multiple myeloma correlate with treatment response. Ann Hematol 89(4):385-389

34. Mileshkin L, Honemann D, Gambell P, Trivett M, Hayakawa Y, Smyth M, Beshay V, Ritchie D, Simmons P, Milner AD, Zeldis JB, Prince HM (2007) Patients with multiple myeloma treated with thalidomide: evaluation of clinical parameters, cytokines, angiogenic markers, mast cells and marrow CD57+ cytotoxic T cells as predictors of outcome. Haematologica 92:1075-1082

35. Cibeira MT, Rozman M, Segarra M, Lozano E, Rosiñol L, Cid MC, Filella X, Bladé J (2008) Bone marrow angiogenesis and angiogenic factors in multiple myeloma treated with novel agents. Cytokine 41(3):244-253

36. Jelkmann W (2001) Pitfalls in the measurement of circulating vascular endothelial growth factor. Clin Chem 47:617-623

37. Marković O, Marisavljević D, Cemerikić V, Vidović A, Perunicić M, Todorović M, Elezović I, Colović M (2008) Expression of VEGF and microvessel density in patients with multiple myeloma: clinical and prognostic significance. Med Oncol 25(4):451-457

38. Sezer O, Niemoller K, Eucker J, Jakob C, Kaufmann O, Zavrski I, Dietel M, Possinger K (2001) Bone marrow microvessel density is a prognostic factor for survival in patients with multiple myeloma. Ann Hematol 79(10):574-577

39. Alexandrakis MG, Passam FJ, Ganotakis E, Dafnis E, Dambaki C, Konsolas J, Kyriakou DS, Stathopoulos E (2004) Bone marrow microvascular density and angiogenic growth factors in multiple myeloma. Clin Chem Lab Med 42(10):1122-1126

40. Belnoue E, Pihlgren M, McGaha TL, Tougne C, Rochat AF, Bossen C, Schneider P, Huard B, Lambert PH, Siegrist CA (2008) APRIL is critical for plasmablast survival in the bone marrow and poorly expressed by early-life bone marrow stromal cells. Blood 111(5): 2755-2764

41. Bonci D, Hahne M, Felli N, Peschle C, De Maria R (2004) Potential role of APRIL as autocrine growth factor for megakaryocytopoiesis. Blood 104(10):3169-3172

42. Winter O, Moser K, Mohr E, Zotos D, Kaminski H, Szyska M, Roth K, Wong DM, Dame C, Tarlinton DM, Schulze H, MacLennan IC, Manz RA (2010) Megakaryocytes constitute a functional component of a plasma cell niche in the bone marrow. Blood 116(11):1867-1875

43. Lemancewicz D, Bolkun L, Jablonska E, Kulczynska A, BolkunSkornicka U, Kloczko J, Dzieciol J (2013) Evaluation of TNF superfamily molecules in multiple myeloma patients: correlation with biological and clinical features. Leuk Res 37(9):1089-1093

44. Terpos E, Katodritou E, Roussou M, Pouli A, Michalis E, Delimpasi S, Parcharidou A, Kartasis Z, Zomas A, Symeonidis A, Viniou NA, Anagnostopoulos N, Economopoulos T, Zervas K, Dimopoulos MA, 
Greek Myeloma Study Group, Greece (2010) High serum lactate dehydrogenase adds prognostic value to the international myeloma staging system even in the era of novel agents. Eur J Haematol 85(2): 114-119

45. Rossi JF, Moreaux J, Hose D, Requirand G, Rose M, Rouillé V, Nestorov I, Mordenti G, Goldschmidt H, Ythier A, Klein B (2009) Atacicept in relapsed/refractory multiple myeloma or active Waldenström's macroglobulinemia: a phase I study. Br J Cancer 101(7):1051-1058
46. Fragioudaki M, Tsirakis G, Pappa CA, Aristeidou I, Tsioutis C, Alegakis A, Kyriakou DS, Stathopoulos EN, Alexandrakis MG (2012) Serum BAFF levels are related to angiogenesis and prognosis in patients with multiple myeloma. Leuk Res 36(8):1004-1008

47. Moreaux J, Sprynski AC, Dillon SR, Mahtouk K, Jourdan M, Ythier A, Moine P, Robert N, Jourdan E, Rossi JF, Klein B (2009) APRIL and TACI interact with syndecan-1 on the surface of multiple myeloma cells to form an essential survival loop. Eur J Haematol 83(2): $119-129$ 